\title{
EL LIBRO DE TOBIT Y EL CUENTO MARAVILLOSO (1)
}

Mary Cruz Burdiel de las Heras

\begin{abstract}
This is a literary study of the Book of Tobit for the analysis of which the thesis is adopted that, besides presenting the characteristics, both thematic and structural, of the biblical narrative, it shows that the functions carried out by the people involved are the same as those which are found in tales of marvel, as suggested by Vladimir Propp, in the differentiation of this type of story.
\end{abstract}

La Biblia es uno de los fenómenos religiosos más extraordinarios de la humanidad. El mérito y la belleza de la literatura bíblica hacen decir a David Gonzalo Maeso (2) que se eleva sobre cualquier literatura, sin exceptuar la griega. Ciertamente hay una gran perfección en todos sus libros por la manera de utilizar el lenguaje, la estructura del hilo narrativo, la certera presentación de los personajes y no falta ningún ornato de los escritores de la antigüedad clásica que no se halle representado en la Biblia; a lo que se puede sumar su alto idealismo; el carácter poético, que aparece incluso en los libros más prosáicos; el contenido filosófico de su temática, aunque no esté expuesta en forma sistemática; el "colorido oriental", término que muchos críticos no aceptan, pues consideran que es, simplemente, la manifestación de una cultura diferente a la occidental; una gran fuerza expresiva, a pesar de la concisión del discurso que se da en la mayoría de los libros.

La diversidad de géneros, de temas y de estilos en ella incluidos, están unidos por la ideología. No puede, por lo tanto, hablarse de una obra, sino de toda una literatura.

El número de libros que componen la Biblia no es siempre el mismo. Básicamente se deben diferenciar dos colecciones: el Canon Palestinierıse, la más breve, formado a partir de los originales hebreos. Este canon se cerró aproximadamente hacia el 250 a.C., por esta razón, no se incluyeron algunos libros, a pesar de estar escritos en hebreo. El Canon Alejandrino o Versión de los LXX, en la que ni el orden ni el número de libros es el mismo del anterior. Esta versión es una traducción al grie- go basada en un texto hebreo antiquísimo, más larga que la palestiniense, en ella se recoge el libro objeto de estudio, Tobit.

El autor del libro de Tobit es desconocido, como ocurre con casi todos los libros bíblicos, ya que el papel del autor no es importante en esta literatura se sabe que vivió en la época post-exílica y la fecha de composición se sitúa entre el 500 y el 100 a.C.

La obra es una combinación de partes narrativas y poéticas, muestra la fuerza creadora de imágenes y símbolos del escritos hebreo la importancia dada al ritmo y a la sonoridad, que también se da en la prosa, es esencial en una cultura oral como lo es toda la cultura semíca, en la que la palabra tiene valor no sólo por su significante, sino, también, por su significado. El autor se muestra como un creador literario de primera magnitud.

Tobit pertenece al grupo de libros denominados hagíografos, un tipo de literatura escrita en ia que el hagíografo, a diferencia del profeta, no es el portavoz de la palabra divina, sino un instrumento de Dios por eso se le respetan sus cualidades personales y sus dotes literarios.

Prescindiendo de si es una obra biográfica o no (el hecho de mezclar la narración con diversos tipos de poesía, hacen pensar en una ficción literaria con un fin moralizador), puede decirse que se trata de una obra narrativa. Su esquema se ajusta al de las narraciones bíblicas que constituyen una unidad en sí, Rut, Tobit, Judit, Ester; éste es muy sencillo: $1^{\circ}$ Prólogo, $2^{\circ}$ Preparación, $3^{\circ}$ Nudo, $4^{\circ}$ o Desenlace, $5^{\circ}$ Epílogo, en el que se da una 
información complementaria de los personajes hasta su muerte.

Los sucesos narrados se sitúan en la época asiria y primera etapa del cautiverio de Israel (S/ VIII-VI a. C.). El problema que plantea Tobit, el justo sometido a prueba por Dios, no es único en la literatura bíblica, ya había sido expuesto en Job y, unos mil años antes, en la literatura sumeria; en los dos, Job y Tobit, hay un desenlace feliz. La diferencia radica en el tono de la obra, Job muestra la amargura del hombre que se enfrenta a una situación que no entiende, se rebela contra ella y exclama:

\footnotetext{
" ¡Pareciera el día en que yo había de nacer y la noche que dijo;" Un varón ha sido concebido"'"
}

Job. 3,3

Tobit, por el contrario, presenta la aceptación, la suavidad, la esperanza en Dios con las siguientes palabras:

Justo eres, Señor, y todas tus obras son (justas)

$Y$ todos tus caminos misericordia y verdad,

y juicio veraz y justo juzgas tú, por siempre jamás.

( $Y$ ahora, Señor), acuérdate de mí, y mírame.

y no te vengues de mí por mis pecados

y por mis ignorancias y las de mis padres,

que pecaron en tu acatamiento.

Tob 3, 2-3

Con ellas Tobit, después de haberse quedado ciego, le pide a Dios la muerte. A partir de este punto comienza a la historia: Tobit no quiere dejar a su familia desamparada económicamente y manda su hijo, Tobías, a que cobre el dinero prestado a Gabaleo. Este viejo le sirve al joven para encontrar el medio con que curar la ceguera de su padre y solucionar la carencia económica, no sólo con el dinero cobrado a Gabaleo, sino, también, con el que aporta Sara al casarse con Tobías. La historia lleva hasta la muerte de los personajes.

Los personajes están perfectamente caracterizados, dan sensación de amabilidad y de unión familiar. El impulsor de la historia es Azarías, como dice llamarse el inicio, o Rafael, como se identifica al final, aunque, aparentemente, se quede en un discreto segundo plano.

El estudio del ambiente es una fuente de información de las costumbres del pueblo biblico. La unidad familiar, tribal y correligionaria se presentan como elemento esencial del sistema de vida; incluye, además, detallada información de un acontecimiento familiar, la boda, que, según D. Gonzalo Maeso, es única en toda la Biblia: se habla del contrato escrito y sellado, del aposento nupcial, del banquete de bodas, de la dote de la novia.

Pero, literariamente, este libro es más de lo dicho hasta ahora, el elemento maravilloso que aparece entronca el discurso narrativo con el cuento maravillos. No corresponde a este estudio el demostrar la veracidad o no de los acontecimientos. Por lo demás, la utilización de una técnica narrativa u otra, no invalida la historicidad de los acontecimientos.

Se ha hecho muy poco para estudiar la Biblia como una realidad literaria, sobre todo, si se compara con la cantidad de estudios de carácter exegético, cuando la Biblia, estudiada literariamente, es un rico caudal de variedad de expresiones literarias, pues no existe ninguna forma conocida que, de una manera u otra, no esté representada. Lo que se pretende hacer con este trabajo es explicar el libro de Tobit según sus razones artísticas.

Tobit puede calificarse como un determinado tipo de cuento, el cuento maravilloso, de acuerdo con lo que Propp propone como necesario para diferenciarlo de otras formas de cuento.

Para él, el cuento maravillos procede del mito, una forma de narración que se transmite oralmente. Si se tiene en cuenta la importancia que la tradición oral ha tenido en oriente, no es de extrañar que el autor de Tobit se inspirara en un esquema conocido, que podría ser tanto de influencia babilónica como hebrea. Los exégetas escandinavos insisten en la importancia de la tradición oral en la cultura hebrea, cuya obra representativa, la Biblia, raras veces utiliza el verbo escribir, lo normal es el uso del verbo decir. El fundador de esta escuela, Nyberg, sostenía lo siguiente (4):

"La forma normal de transmisión en el antiguo Oriente es la tradición oral.

-El Antiguo Testamento es la plasmación escrita directa, de la tradición oral, realizada por la comunidad judáica postexillica".

El cuento maravilloso fue creado por el pueblo, es muy antiguo y tiene carácter popular. Si se busca la antigüedad del libro de Tobit en relación con la cultura en que se crea, no la hay tal, pues es un libro muy moderno. Sirva esto para insistir en que la tesis planteada es que el libro de Tobit es una obra escrita que sigue el esquema propuesto por Vladimir Propp para identificar el cuento maravilloso. Debido a que casi toda la literatura hebrea externa a la Biblia se ha perdido, resulta muy difícil encontrar antecedentes de esta obra que cho- 
ca con el carácter realista de la literatura bíblica. Tobit, por el contrario, se enfrenta con el elemento fantástico representado por el corazón, el hígado y la hiel del pez, dados como objetos mágicos a Tobías por el angel para que le ayuden a llevar a cabo sus empresas. Lo fantástico está relacionado con la religión. El nexo relato-maravilloso-rito es esencial para Propp, puesto que el culto y la religión son una institución en cualquier sociedad, por lo tanto el relato ha conservado numerosas huellas del rito y hay que relacionarlo con manifestaciones concretas de la religión; en el caso de Tobit, la religión del pueblo judío.

Todo el libro de Tobit es una enseñanza moral que se explicita en el cap. 4 con el bellísimo poema de los consejos de Tobit a su hijo, que constituye un compendio de los preceptos del Pentateuco

A todo el que trabaja en tu provecho págale al instante su salario;

y el salario del jornalero no pernocte en tu poder.

Y si tú trabajares en servicio de Dios, te será pagado tu jornal.

Ten ojo sobre ti, hijo, en todas tus obras, y muéstrate bien criado en toda tu conducta.

Lo que detestas que haga otro contigo

mira no lo hagas tú con otro.

Tob. $4,14-15$

en las acciones de Tobit y en la respuesta del angel

Bueno es oración con ayuno;

y limosna con justicia.

Bueno es poco con justicia

antes que mucho con injusticias.

Bueno es hacer limosnas

antes que atesorar oro.

Tob 12,8

El cuento maravilloso, al igual que el de animales, contiene siempre una enseñanza moral, lo que varía es la forma de darla.

La estructura especial de los cuentos maravillosos la expone Propp de la siguiente manera:

"Se puede llamar cuento maravilloso desde el punto de vista morfológico a todo desarrollo que partiendo de una fechoría (A) o de una carencia (a) y pasando por las funciones intermedias culmina en el matrimonio (W) o en otras funciones utilizadas como desenlace. La función terminal puede ser la recompensa ( $F)$, la captura del objeto buscado o de un modo general la reparación del mal (K), los auxilios y la salvación durante la persecución (Rs) etc. A este desarrollo le llamamos secuencia. Cada nueva fechoría o perjuicio, cada nueva carencia origina una nueva secuencia.
Un cuento puede comprender varias secuencia, y cuando se analiza un texto hay que determinar en primer lugar de cuántas secuencias se compone.

Una secuencia puede ir inmediatamente después de otra, pero también puede aparecer entrelazadas, como si se detuvieran para permitir que se intercale otra secuencia" (5). "...el género de cuentos que comienza con una disminución o un daño causado a alguien (rapto, expulsión del hogar, etc), o bien con el deseo de poseer algo (el rey envía a su hijo a buscar el pájaro de fuego) y se desarrolla a través de la partida del protagonista de! hogar paterno, el encuentro con un donante que le ofrece un instrumento encantado o un ayudante por medio del cual halla el objeto de su búsqueda. Más adelante, el cuento presenta un duelo con el adversario (la forma principal es el duelo con la serpiente), el regreso y la persecución.

Con frecuencia, esta composición presenta determinadas complicaciones..." (6).

Lo que diferencia al cuento maravilloso, de acuerdo con Propp, no son los motivos, que pueden variar, sino ciertas unidades estructurales, que se presentan como constantes, y considera que las funciones de los personajes son las partes fundamentales. Estas funciones son limitadas, aunque no todos los cuentos tengan el mismo número de ellas, pero la falta de alguna de ellas no implica el hecho de que la sucesión no sea siempre la misma. Por ejemplo, el envío y la partida, relacionados con la búsqueda son constantes, pero quien envía, quien parte o el porqué pueden variar.

Tobit, como ya se ha dicho, es una obra escrita, por lo tanto contiene ciertas transformaciones, una de ellas es el entrelazar dos líneas de acción, con lo cual algunas de las funciones se repiten. Sin embargo, no son dos cuentos, ya que la segunda línea contribuye a resarcir la carencia inicial. Además, hay que añadirle las particularidades propias de la narrativa bíblica. Pero al comparar las funciones que desempeñan los personajes de esta obra con las del cuento maravilloso, puede comprobarse que se ajustan a la estructura particular de esta narración.

La historia, según lo ya visto, es simple el núcleo que la origina, la ceguera de Tobit, tiene un feliz desenlace. Esta ceguera, a su vez, desencadena los diferentes acontecimientos y funciones de los personajes.

De acuerdo con el esquema narrativo bíblico, el libro se puede dividir:

Prólogo: $\quad$ cap. 1, 1-2. Se da, por medio de un narrador omnisciente, la genealogía del personaje, la fecha y lugar de los acontecimientos.

Preparación: Cap. 1,3 a 3,17. Tobit, como narrador protagonista, narra la situación 
del pueblo judío en el destierro y la suya propia. Al referir su conducta, introduce los valores que hay que restituir. por mantenerlos, él fue apresado, perdió sus bienes y, finalmente, quedó ciego. En el capítulo 3 se introduce otro personaje que no pertenece a la familia de Tobit, Sara.

Nudo: $\quad$ cap. 4,1 a 11,4 . Se narra el envío y partida de Tobías; el encuentro con el angel; la lucha contra el pez; el matrimonio con Sara; la cobranza del dinero y la vuelta. Desde aquí hasta el final aparece, otra vez, el narrador omnisciente.

Desenlace: cap. 11,5 a 13. Comprende la llegada a Nínive y la curación de Tobit.

Epílogo: cap. 14. Da una breve información de los personajes hasta la muerte de todos ellos.

En los cuentos maravillosos, Propp encuentra que, habitualmente, comienzan con lo que Ilama situación inicial, en la que se enumera a los miembros de la familia, en este caso: Tobit, Ana, y Tobías (Tob. 1,9). Este principio va seguido de las funciones de los personajes, recordando que en Tobit hay variaciones de diversos tipos, por ejemplo, la función de la transgresión que, frecuentemente, la realiza el héroe buscador, la lleva a cabo el héroe víctima, Tobit transgrede las órdenes de Senaquerib, el agresor:

"Y en los días de Senaquerib iba yo cada día por toda mi parentela y los consolaba, y repartía a cada cual de mis haberes, según que podía, y hacía limosnas a mis hermanos (de mi linaje)"

Tob. 1,16

Todo esto acontece en la situación inicial, en la cual, además, se introduce el ambiente. De acuerdo con Propp, el espacio representa en estos cuentos, un doble papel, es indispensable para el relato, pero, a veces, parece no existir. En Tobit se fijan unos espacios concretos: Nínive, en Siria, y Ecbátana, en Media, pero lo que le importa a la narración es la presentación del aspecto psicológico del ambiente de Nínive: angustia, opresión y temor; de él se deriva la carencia de uno de los valores más importantes para el desarrollo de la trama, la falta de libertad para practicar una religión.

\section{ANALISIS DE LAS FUNCIONES DEL CUENTO MARAVILLOSO EN EL LIBRO DE TOBIT (7)}

1 (I) ALEJAMIENTO. Tobit es llevado cautivo a Nínive (Tob, 1, 10). Este cautiverio es suficiente base para una desgracia, pero está atenuada por la relativa libertad que Enemesar le concede al nombrarle procurador (Tob. 1,13)

2 (II) PROHIBICION. No está expresada explícitamente, se deduce por oposición al comportamiento de Tobit, lo que causa, posteriormente, su castigo. Enemesar muere y su hijo Senaquerib, que le sucede, prohibe enterrar a los judíos asesinados por él.

3 (III) TRANSGRESION. Tobit, apesar de la prohibición, continúa ayudando a sus hermanos (correligionarios) y sepultando, secretamente, a los muertos (Tob. 1, 17-19). Vuelve a repetir la transgresión, ya en tiempos de Asaradón (Tob. 2,8).

4 (V) INFORMACION. Al buscar Senaquerib los cuerpos de los asesinados y no hallarlos, uno de los de Nínive delata a Tobit.

La función IV, INTERROGATORIO, no está narrada, posiblemente debido a la concisión del relato bíblico, la da por sobreentendida.

5 (VIII) FECHORIA. Inmediatamente llega la desgracia como contraste con la situación inicial feliz que se había dado. Los bienes de Tobit le son arrebatados, él tiene que ocultarse para no ser asesinado (Tob. 1, 19-20). Como consecuencia de la segunda transgresión se le forman cataratas en los ojos (Tob. 2, 10)

El infortunio no es solamente económico y físico, sino existencial, lo que le da mayor profundidad que la de un simple cuento maravilloso.

\footnotetext{
"Y ahora haz conmigo según tu beneplácito; dígnate recoger en paz mi espíritu

para que sea desatado de sobre la faz de la tierra y me convierta en polvo;

pues me aprovecha morir (antes) que vivir; porque oí escarnios mentirosos,

y es mucha dentro de mí la tristeza
}

(Tob. 3,6)

Las funciones anteriores a ésta última, son la parte preparatoria del cuento, mientras que la FECHORIA va ligada a la trama.

El logro de Tobit introduce aquí, simultáneamente, al otro personaje víctima, Sara de la que se ha prendado el demonio Asmodeo. Puede considerarse como una especie de rapto ya que no deja que ningún hombre la tome por esposa. La relación entre estas dos acciones se hace al final del 
capítulo, cuando el narrador omnisciente adelanta el desenlace:

"Y fue enviado Rafael para remediar a los dos... En un
mismo tiempo volviendo Tobit (del patio), entró en su
casa y Sara la de Ragüel bajó de su azotea" (Tob.3, 17).

La historia parte de Tobit, puesto que lo referido a Sara es consecuencia de lo anterior.

6 (VIII-a) CARENCIA. Aunque se ha hecho referencia a varias, la que hace avanzar la historia, es la económica. Tobit está seguro de que Dios va escuchar su petición de morir, entonces empieza a arreglar todos sus asuntos y se acuerda del dinero que le había prestado a Gabaleo hacía veinte años, por lo que decide ped írselo.

7 (IX) MEDIACION. Es el momento en que hace su aparición el héroe buscador, Tobías, por medio de una orden. Tobit llama a su hijo para que se encargue del asunto (Tob. 4,3).

8 (X) PRINCIPIO DE LA ACCION CONTRA$R I A$. El héroe buscador, después de un diálogo sostenido con el héroe víctima, decide actuar:

"(Entonces) respondiendo Tobías dijo (a Tobit su padre): -Todo cuanto me has mandado lo haré, padre".

(Tob. 5,1$)$

9 (XI) PARTIDA. Como consecuencia de la aceptación se produce la partida, con lo cual la narración abandona al héroe para seguir al héroe buscador, hasta el cumplimiento de la tarea mágica, entendida como difícil. Tobías no conoce a Gabaleo, ni el camino a la Media. En realidad son tres las tareas que ha de cumplir para llegar a la restitución de la carencia: a) matar al pez, b) expulsar al demonio Asmodeo, c) cobrar el dinero a Gabaleo.

En este momento de la partida, hace su aparición un personaje decisivo, el donante. Tobías sale a buscar quien le acompañe y, por casualidad, como ocurre habitualmente en el cuento maravilloso, encuentra al donante, Azarías, (Tob. 5,4). Recibe el nombre de donante porque él proporciona el medio que ha de permitir solucionar el daño, los daños, en este caso.

10 (XII) PRIMERA FUNCION DEL DONANTE. El héroe sufre una prueba. Tobías es atacado por un pez y, puesto que Azarías es el que va guiando y le lleva hasta el Tigris, tiene validez lo indicado por Propp de que es el donante el que pone a prueba al héroe (Tob. 6,1)

11 (XIII) REACCION DEL HEROE. Tobías reacciona positivamente y sale triunfante de la prueba con la ayuda del donante. El duelo se resuelve rápidamente, puesto que no es el punto culminante del cuento maravilloso. En Tobit se explica con muy pocas palabras, Tobías, al ver el enorme pez que quería tragarse su píe, le grita al angel:

“-Señor, me embiste.

Mas el angel le dijo:

-Toma el pez cógele por las agallas y tíralo hacia tí.

$Y$ asió el muchacho el pez y lo subió a la tierra. $Y$ comenzó a palpitar junto a sus pies"

(Tob. 6, 2-3)

El duelo se desarrolla en el agua, elemento estrechamente vinvulado con el cuento maravilloso, al igual que los animales marinos: el pez, la serpiente acuática. Esto hace pensar que el duelo se relacione con algún mito marino.

12 (VIX) RECEPCION DEL OBJETO MAGICO. Al ancanzar la victoria, el héroe recibe del donante el objeto mágico, tres objetos en Tobit: el corazón, el hígado y la hiel del pez (Tob. 6,4)

Después de recibir el objeto mágico pareciera como si el héroe del cuento maravilloso no hiciera nada, y el auxiliar mágico el que resolviera todo. Para Propp esto no hace desmerecer el alcance morfológico del héroe, puesto que lo que cuenta son las intenciones y éstas se revelan a través de las órdenes que da sus auxiliares, que en Tobit se manifiestan por medio de la oración.

13 (XV) DESPLAZAMIENTO. EI héroe es guiado por el donante, un donante amistoso que cumple en la historia más funciones que las que le son comunes. El se encarga de llevarle al "otro reino", o sea, desde Nínive a Ecbátana. (Tob. 6, 10)

La llegada a Ecbátana introduce la función típica del cuento maravilloso, el rescate de la princesa y el posterior matrimonio. Sin embargo, ésta no ha sido la causa directa del alejamiento, es sólo una más de las órdenes que ha recibido el héroe de parte de su padre:

"Toma ante todo mujer del linaje de tus padres
no tomes mujer extraña
que no sea de la tribu de tu padre" (Tob. 4,12 ).

Es importante resaltar este mandato puesto que es uno de los más claros reflejos de la influencia religiosa de la cultura donde se crea la obra, además contrasta con lo que Propp dice que ocurre en el cuento maravilloso, en el que lo normal es la exogamia, mientras que en Tobit se insiste en la endogamia, no sólo por el consejo del padre, sino también por lo que ángel le dice a Tobías varias veces: 


\begin{abstract}
"Hablaré sobre ella para que te sea dada por mujer, pues a tí corresponde su herencia, y tú eres el único de su linaje". (Tob. 6, 12)
\end{abstract}

El encadenamiento de las funciones que siguen con las precedentes se relaciona siempre de la misma manera, un personaje se entera de algo por mediación de otro: el ángel le hace saber a Tobías que él es el único que puede casarse con Sara. Esto es el vínculo con la función que sigue.

La realización de esta nueva aventura hace que se repitan algunas de las funciones ya descritas y se produzcan otras nuevas. (8)

A (VIII) FECHORIA. Es la primera que se da a conocer. Asmodeo, un demonio, se ha apoderado de Sara y ha asesinado a todos los esposos que ha tenido en la primera noche de bodas. El hecho de que el raptor sea un demonio es una deformación posterior causada por influencia religiosa. (Tob, $3,8)$

B (VIII-a) CARENCIA. Consiste en que Sara no puede consumar ninguno de sus matrimonios. Los siete esposos anteriores habían sido asesinados por Asmodeo.

C (IX) MEDIACION. Tobías es llamado por la orden del ángel. (Tob. 6,16)

Ch (X) ACEPTACION. No está expresada, pero se deduce por las acciones posteriores.

D (XIV) RECEPCION DEL OBJETO MAGICO. $\mathrm{EI}$ héroe ha recibido anteriormente el objeto, pero no la manera de utilizarlo. El donante se encarga, en este momento, de explicarle el rito que ha de seguir:

\footnotetext{
"Mas tú cuando la tomes como esposa, entrado en el tálamo, durante tres días te abstendrás de llegarte a ella, y no harás otra cosa que darte con ella a la oración.....Y la misma noche tomarás del rescoldo de los perfumes y pondrás encima parte del corazón y del hígado del pez y harás humo, y lo olerá el demonio y huirá" (Tob. 6, 17)
}

El ángel le explica detalladamente todo el ritual y lo que acontecerá cada noche hasta que en la tercera pueda consumarse el matrimonio.

$\mathrm{E}$ (XVIII) EL AGRESOR ES VENCIDO EI rito mágico-religioso de quemar el corazón y el hígado, hacen que el demonio huya a Egipto a donde es persequido por el ángel que le aprisiona. De esta manera el ángel cumple una función más de las que normalmente corresponden al donante.

F (XXXI) EL MATRIMONIO. LA RECOMPENSA es el matrimonio (Tob. 8, 19-20). En este caso el héroe recibe mujer y la mitad del "reino" y el "reino" completo cuando muera el suegro. Lo nor- mal en el cuento maravilloso es que el héroe herede al suegro y no al padre, aunque, a veces, después del matrimonio el héroe vuelve a su casa.

En Tobit hay una combinación de las dos soluciones, el héroe vuelve a su casa pero sólo hasta que sus padres mueran, después retorna al "reino" del suegro. Esta modificación está de acuerdo con uno de los valores que es necesario restituir, el amor filial.

El episodio del matrimonio no es una aventura accesoria en el relato, ayudará a solucionar la carencia económica inicial, para ello es necesario llevar a cabo la función que motivó la partida y que constituye el hilo principal de la historia.

14 (XIX) REPARACION. Llega el momento de cobrar el dinero a Gabaleo, en Rages de la Media. Como consecuencia del tono de suavidad de la obra, esta función se lleva a cabo fácilmente, no hay enfrentamiento, ni siguiera es el héroe el que la realiza, sino el donante que vuelve a efectuar una función más de las que le son normales. (Tob. $9,2)$

$15(\mathrm{XX})$ LA VUELTA Se realiza casi inmediatamente (Tob. 11, 1-4) después de los catorce días que dura la celebración de las bodas. La rapidez con que se inicia la vuelta es la misma con que se había dado la partida y el combate, ya que en el cuento maravilloso se omite el movimiento.

La vuelta no es el final de las funciones, sino que el desenlace se alcanza con una segunda victoria, en esta ocasión sobre la enfermedad, realizada con la ayuda del tercer objeto mágico, la hiel. (Tob. 11, 7-8)

Debido al carácter religioso del libro se resalta más la restitución de esta carencia que la de la económica.

La importancia artística y temática no se conoce con el solo análisis de las funciones; ya se han mencionado los valores literarios; las cualidades del autor, especialmente su vana psicológica; el tono de afabilidad de la obra; su alto contenido moral, la posibilidad de acercarse un poco más a estos aspectos la brinda el estudio de otros elementos del cuento maravilloso, como son los atributos y, sobre todo, las motivaciones de los personajes.

ATRIBUCIONES DE LOS PERSONAJES. Por atributos se entiende el conjunto de cualidades externas de los personajes, estas son variables debido a las diversas influencias que sufre el cuento; aunque conserve restos de paganismo, de costumbres $y$ de ritos de la antigüedad, no puede sustraerse a las 
influencias de su realidad histórica, de la literatura, ya sea suya o de los pueblos vecinos, y, en especial, de la religión. Y qué más rito pagano que la quema del corazón y del hígado del pez en el rescoldo de los perfumes, es todo un sahumerio para purificar a Sara de la influencia maléfica de Asmodeo, sin embargo está contrarrestado con la oración a Yahweh. Esta movilidad del cuento le permite la variabilidad de los atributos de los personajes y el remplazar unos por otros.

Tres son los apartados fundamentales en el estudio de los personajes: ASPECTO y NOMENCLATURA, PARTICULARIDAD DE LA ENTRADA EN ESCENA, HABITAT. En el libro de Tobit con respecto al aspecto, son tan importantes las cualidades externas como las morales.

ASPECTO y NOMENCLATURA. Tobit, anciano, ciego caracterizado por su religiosidad, sabiduría y resignación.

ENTRADA EN ESCENA. Se presenta a sí mismo mostrando su aspecto religioso.

HABITAT. Nínive. El lugar influye para que la historia exista

ASPECTO y NOMENCLATURA. Tobías, joven, hijo único de Tobit. Tiene un perro que siempre le acompaña la presencia del perro le da mayor colorido a la obra y contribuye al tono de afabilidad. Moralmente se caracteriza por el amor filial y la obediencia.

ENTRADA EN ESCENA. Es llamado por el padre para encargarle el cumplimiento de la tarea difícil.

HABITAT. La casa de los padres. Relacionada con Tobías, la ciudad de Nínive no tiene ninguna importancia. El vive en casa de sus padres y esa es la que tiene que abandonar, como es lo común en el cuento maravilloso.

ASPECTO y NOMENCLATURA. EI donante se identifica a sí mismo con el nombre de Azarías, que significa Socorro de Yahweh, posteriormente dice llamarse Rafael, Medicina de Dios o Dios Sana. Nótese la relación entre los nombres y la función desempeñada por este personaje, la ayuda no viene de él, sino de Dios. Joven gallardo, de píe, ceñido. En la literatura bíblica desde el mandato de la celebración de la Pacua, en Exodo, el estar ceñido y de píe indica la disposición a partir.

ENTRADA EN ESCENA. Aparece súbitamente, como corresponde a la aparición del donante.

HABITAT. El caracter angélico del personaje no necesita un lugar físico, su hábitat es "la presencia de la gloria del Santo" (Tob. 12, 15)
MOTIVOS DE LOS PERSONAJES Son los móviles y los fines de los personajes, que les llevan a realizar una acción.

Su estudio pone de manifiesto los valores que hay en la obra. Según Greimas el cuento maravilloso presenta un mundo de valores invertidos, su restablecimiento despeja el camino hacia el restablecimiento de la ley. Se da la alternativa entre el hombre alienado y el hombre en posesión de valores, que demuestra y afirma su libertad individual al transgredir la prohibición, por medio de lo cual se restablece el orden, indispensable para la reintegración de los valores.

Los motivos de los personajes del libro de Tobit son los valores que hay que restituir en oposición a los que prevalecen en la sociedad presentada.

TOBIT. El temor de Dios, manifestado por su caridad al dar limosna y enterrar a los muertos. Guardar las costumbres religiosas y la unión familiar.

Valores invertidos, la apostasía de su pueblo y la convivencia con los gentiles, tantas veces sancionada en la Biblia.

TOBIAS. El amor a los padres, la obediencia, aunque de acuerdo con el significado general de la obra, el más significativo es el de la fidelidad matrimonial y la continencia.

Valores invertidos, la concupiscencia y lujuria con que, en la literatura bíblica, se asocia a los pueblos paganos.

AZARIA (RAFAEL). Es el representante de Dios que le había enviado para curar a Tobit y liberar a Sara del demonio. Su misión era la de llevar las oraciones y acciones de los hombres a Dios.

Después de esta explicación, su motivo puede enunciarse como ayudar al justo para mostrar la recompensa de las buenas acciones, en oposición al castigo de los malvados.

LA TRIPLICACION Propp considera la triplicación como otro de los elementos del cuento. En el libro de Tobit se presenta de la siguiente manera: 3 son los personajes que tienen a su cargo la realización de las funciones.

3 noches son necesarias para poder consumar el matrimonio

3 las tareas que tiene que realizar el héroe

3 los objetos mágicos que ayudan a resarcir la carencia. 
Pero el cuento maravilloso es creado por el pueblo, es un cuento folklórico que no puede evadir el influjo de la cultura donde nace, más bien se hace eco de ella, de ahí que aparezca otro número significativo para la cultura hebrea, el 7. Así:

7 son los esposos muertos por Asmodeo

14 , un múltiplo de 7 , los días que dura la celebración de la boda en casa de Ragüel

7 días la celebración en casa de Tobit

7, los hijos de Tobías

La importancia que se da a las relaciones familiares entre los personajes, incluso con Gabaleo, son una muestra del aspecto folklórico que recoge esta obra, el de una cultura tribal regida por unos valores que concentra, magistralmente, el poema gnómico con que Tobit despide a su hijo.

\section{NOTAS}

(1) La Vulgata unificó los nombres de Tobeith, el padre, y Tobeias, el hijo. Siguiendo el texto utilizado, se denomina al padre Tobit y al hijo Tobías, que está más de acuerdo con el original.

(2) David Gonzalo Maeso. Manual de historia de la literatura hebrea (Ed. Gredos. Madrid, 1960). passim

(3) No se sabe si primitivamente fue escrito en hebreo o aremeo, pues el original se ha perdido. Se conservan nueve versiones antiguas, que coinciden en los elementos esenciales tanto históricos como doctrinales: los mismos personajes, los mismos acontecimientos, colocados en el mismo orden; las mismas enseñanzas, distribuidas de igual manera.

Una mayor información se puede encontrar en Sagrada Biblia, versión de J.M. Bóver y F. Cantera. BAC. Madrid, 1947. Esta fue la utilizada para el trabajo por contener los códices Sinaítico, Vaticano y la versión de la Vulgata.

En las citas que se hacen del libro de Tobit, las partes incluidas entre paréntesis se debe a que no se encuentran en la Vaticana y sí en alguno de los otros textos.
(4) L. Alonso Schökel y otros. Profetas. (tom.I Ediciones Cristiandad. Madrid, 1980) p. 70

(5) Vladimir Propp. Morfología del cuento (2 ed. Ed. Fundamentos. Madrid, 1974), p. 101

(6) V. Propp. Las raices históricas del cuento (3 ed. Ed. Fundamentos. Madrid 1981) p. 17.

(7) El orden de las funciones que se dan en el libro de Tobit, se enumera con cifras arábigas; entre paréntesis y con numeración romana, se ponen las que corresponden a la dada por Propp en Morfología del cuento

(8) Estas funciones se identifican con letras por orden alfabético y se mantiene el mismo sistema para las correspondientes señaladas por Propp.

\section{BIBLIOGRAFIA}

Alonso Schökel, I. y otros. Profetas. Ediciones Cristiandad. Madrid, 1980

Gonzalo Maeso, D. Manual de historia de la literatura hebrea. Ed. Gredos. Madrid, 1960.

Pinon, R.El cuento folklórico. Ed Universitaria de Buenos Aires. Argentina, 1962

Propp, V.Las transformaciones del cuento maraviIloso. Rodolfo Alonso editor. Cuadernos de semilogía. Buenos Aires, 1972

Morfología del cuento, 2 ed. Ed. Fundamentos. Madrid, 1974.

Las raíces históricas del cuento. 3 ed. Ed. Fundamentos. Madrid 1981.

Sagrada Biblia. Versión de J.M. Bóver y F. Cantera. BAC. Madrid, 1947 